\title{
Case Reports of Two Japanese Female Patients' Reintegration into Society: Discussing the Interactions between a Patient's Personality and Group Mentality
}

\author{
Masayo Uji \\ Department of Bioethics, Kumamoto University Graduate School of Life Sciences, Kumamoto, Japan \\ Email: ujimasayo@hotmail.co.jp
}

Received 24 November 2015; accepted 19 December 2015; published 23 December 2015

Copyright (C) 2015 by author and Scientific Research Publishing Inc.

This work is licensed under the Creative Commons Attribution International License (CC BY).

http://creativecommons.org/licenses/by/4.0/

c) (i) Open Access

\begin{abstract}
Based on the experiences of psychiatric patients who were in the process of rehabilitation after a significant period of rest and recuperation, the author aimed at analyzing the phenomena that facilitate as well as hinder patient maladjustment, in order to identify ways for clinical psychiatry to support patients' rehabilitation processes. Two female patients with pathological personality traits who were in the process of rehabilitation were chosen. One attended a community center that offers employment for people with mental disorders, followed by a vocational rehabilitation center for the unemployed; the other returned to an ordinary job for which she was qualified. The author first investigated the interactions between their personalities and the group mentalities in their workplaces, and then analyzed these interactions using psychodynamic theories. The dynamic interactions between these patients' personality pathologies and the group mentalities of the workplaces they chose for their rehabilitation seemed to play a crucial role in determining whether they experienced maladjustment or not. Various phenomena experienced by an individual in a community setting should not be ascribed solely to either the person's personality or the community group mentality, but rather to the interaction between the two. Community centers for people with mental disorders must provide support that facilitates the accomplishment of the original purposes of the group, but also helps each group member improve their self-esteem. At the end of this article, the author argues that the narcissistic need for approval cannot be dismissed simply as pathological, but should be seen as a ubiquitous phenomenon in the contemporary Japanese ethos.
\end{abstract}




\section{Keywords}

\section{Reintegration into Society, Personality Pathology, Group Mentality, Maladjustment, Rehabilitation,} Narcissistic Needs

\section{Introduction}

One of the most crucial tangible goals in contemporary psychiatry is to achieve patient rehabilitation in the community. When a patient resumes contact with the community after a significant period of recuperation, it is common for previously inconspicuous personality characteristics to manifest gradually, or in some cases, rapidly. This sometimes helps the treating psychiatrist understand the patient's personality pathology and hypothesize ways in which it may have played a significant role in their earlier maladjustment. The personality characteristics are usually articulated using a combination of the following terms: problems concerning self-esteem or ego-ideal (Freud, 1914); desire to be admired; abandonment fear; over-adjustment; blind obedience; un-integrated grandiose-self; and narcissism. It is undeniable that all of these factors contribute to the recurrence of patients' crises of maladjustment. In psychotherapy it usually becomes clear that patients have rarely experienced happiness in creative activities, or in contributing to society, for example by way of their job. Their ego seems to have been more invested in primitive narcissistic needs, which appears to determine their way of interacting with the group to which they belong. Their psychological needs are usually unmet, resulting in a variety of symptoms that bring about failure to reintegrate into society. These processes are usually observed in the cases of patients with considerable narcissistic needs.

In addition, it is crucial to examine how group mentality can facilitate a patient's return to a society, as well as what group characteristics contribute to patient difficulties. In Japan, patients often have a significant period of rest following a breakdown, then choose to return to their old workplace (or another where they can utilize their skills), or to welfare facilities that provide rehabilitation for patients with mental disorders. Which would better facilitate patients' reintegration into society? Do group mentality and culture influence the manifestation of mental symptoms as well as personality pathologies? The best way to answer these questions is to scrutinize clinical materials in detail.

\section{Methods}

The author selected the following two cases and then used psychodynamic theories to analyze the dynamic interactions between the patients' personalities and the group mentalities in their respective rehabilitation workplaces, in particular referring to "Experiences In Groups," written by Bion (1961).

\subsection{Ms. A}

Ms. A was raised in a pre-modern manner, being separated from her mother and father during infancy, even though her mother and father were not necessarily incapable of child-rearing. The fact that her brother, who was only one year younger than her, was raised by her parents throughout infancy, childhood, and adolescence, provides evidence of their ability to parent. Ms. A's separation from her parents contributed to her inability to establish sound self-esteem, which further drove her to focus on getting attention and admiration and to avoid being overlooked within a group. Following a significant period of recuperation, she returned to work that made use of her professional skills. Her dependency on the group and its members activated mutual controlling interactions.

\subsection{Ms. B}

Since childhood, Ms. B had believed herself to be a favorite in her various groups. She used to instinctively adhere to a popular person who "deserved" her idealization, and utilized him/her as a tool for her comfort, as if the person were a part of herself. She always required the person to side with her, and when this requirement was not fulfilled, she lost her temper. Feelings underlying this behavior included envy, loneliness, low self-esteem, and shame, all of which were painful for her to recognize. She had been unable to receive emotional support 
from her mother since infancy as her mother had a developmental disorder. The author assumed this contributed to the development of her grandiose narcissistic self, as did her father's blind love for her as long as she fulfilled his expectations, and his expressly valuing her over her older brother. After her breakdown, she obtained several part-time jobs, none of which she was able to hold down for more than a year. Eventually she started attending a community center for people with mental disorders and a vocational rehabilitation center for the unemployed, both of which elicited her feelings of envy and aggression. Features of the group dynamics at both facilities included boundary violation, control, elimination, and confrontation.

At the end of the Discussion, the author proposes how patients should be treated during the rehabilitation period after their breakdowns. Furthermore, the author discusses their attitudes and behaviors in society with reference to a few Japanese psychiatrists’ ideas regarding the relationship between the contemporary Japanese socio-cultural background and individual mentality.

\section{Results}

\subsection{Ms. A}

Ms. A is a lady in her mid-thirties who works at a welfare facility for elderly people. She experienced her first breakdown when she was in her mid-twenties, due to a breakup with her boyfriend. She got married when she was in her late twenties, but divorced within five years and suffered a second breakdown. A few years into her treatment the author became her consulting psychiatrist, and one year later, she secured a job that utilized her professional skills. She worked hard and tried to fulfill what she perceived as her colleagues' expectations. At first sight, this attitude toward her job and her colleagues appeared to derive from the desirable ego-ideal, but over a period of months her therapist, the author of this article, identified the overly altruistic and masochistic aspects of her personality. She felt pressured by her colleagues with regard to some of their requests. In therapy, she said they took advantage of her whenever they wanted to, and never appreciated her, but she never stopped her obedient and self-sacrificial behavior. This dynamic also occurred with Ms. A's mother, who often hinted at financial difficulties and who Ms. A provided with generous help. When Ms. A disclosed her poor physical condition to her colleagues, all became somewhat interfering, but Ms. A followed all the advice they provided, good or bad. It seemed to me that even being controlled by her colleagues was preferable to losing their attention. Assuming that her colleagues actually pushed her to do things against her will, her therapist theorized that her inability to refuse was due to a fear of isolation magnified by her perception of being coerced. Her inability to refuse indicates the lack of the "capacity to be alone” (Winnicott, 1958), prompting her to intensely seek any objects who would support her self-esteem, which had not been developed by her mother during infancy through omnipotent experience. During her adolescence, she came to realize that the best way to get attention was by entertaining, showing devotion to, or depending on others.

Of particular note is that Ms. A's workplace is in a rural area, where people are cooperative and accustomed to reciprocal care. In this culture, her need to control others through dependency and service could most likely be fulfilled. Invitations to several informal after-hours activities organized by small groups of coworkers also temporarily satisfied Ms. A's need for others' attention. Another proof of the benefit of her rural location can be seen in the period during which she lived in an urban area while married. Her workplace at that time was characterized by an individualistic atmosphere, and everyone was required to be independent. Ms. A lost the motivation to attend work, which was followed by a period of absence without notice and by somatic symptoms, presumably because her colleagues reacted to her with indifference. This somatic reaction could be interpreted as a consequence of experiencing the loss of her idealized object image. As a result, she drifted from job to job. During psychotherapy, she sometimes says that she accepts good treatment as her due for devotional behavior, but is not satisfied by it and is constantly seeking an undefined and unrealistic improvement in it. She always desires others' approval, sympathy, and appreciation, which she also expects from me in therapy sessions.

Another of Ms. A's behaviors during her married life provides strong evidence that she can lose even the ability to discriminate between right and wrong when potential actions can gain her the momentary approval of others. The absence of colleagues' praise and attention and her inability to wait alone for her husband, who worked at night, contributed to her beginning work as a hostess, although she initially said the decision was taken to help relieve her husband's debts. A few years after marriage, she gradually began exhibiting anti-social behaviors such as shoplifting and abusing illegal drugs. She also consented to a man's wish that she enter prostitution. She said she wanted the man to praise her more than the other prostitutes. These acts were also partially a subcons- 
cious protest against her husband, and at a deeper level against her mother. The praise of the man who invited her into prostitution brought about a transient pleasure that relieved her feelings of emptiness. However, this man sexually abused her using physical violence, and threatened her life. This sadistic treatment even caused her pleasurable excitement, she disclosed to me in one session. She said she felt that she was controlling men by offering sex, a conviction she still has now. On the occasions when this technique failed, she felt intense envy and aggression toward any woman who had a satisfactory relationship with their partner.

To summarize the interaction between Ms. A's personality and group mentality: her inability to be alone and her continuous need for attention made her comply with the requests of the group, while also driving her attempts to control the group through self-devotion, self-sacrifice, and dependence. When the group was collectively minded in terms of intervening in her life in meddlesome ways, it prevented her from acting out. On the other hand, when the group mentality did not permit her to be dependent, and others were not manipulated by her dependence, she quickly took to self-destructive behavior as an expression of protest.

\subsection{Ms. B}

Ms. B experienced a breakdown when she was in her early thirties, following the breakup of an affair with a married work colleague. She thought the man was handsome, and more importantly, that her female colleagues agreed. This adulterous relationship began in her early twenties. It satisfied her needs to be superior to other women, and she never considered that he would not divorce his wife and marry her. Therefore, when he confessed that he was unable to marry her, her narcissism was seriously wounded and the event was very traumatic. This life event acted as a trigger and necessitated her receiving psychiatric care, which has continued for more than a decade up to this point.

In her early forties, her final employment option was to attend a community center that offers employment for people with mental disorders, a situation that was hard for her to accept due to her inflated pride. During the decade prior to this decision, she tried to get a part-time job that she expected would heal her narcissistic wounds. However, in a blow to her self-esteem, she was unable to learn the relevant job skills; she blamed this failure on her female senior colleagues' cold attitudes toward her and their lack of support. Her therapist's recommendations that she clarify and write down what she could not understand, and ask for help when necessary, were both alien and distasteful to her. Instead, she complained that she was harassed by her colleagues. It seemed she did not focus on acquiring job skills, but instead on the interpersonal dynamics with her colleagues. Therefore, she was unable to hold a job for more than three months, the minimum period being three days. Every time she quit a job, she would stay at home for a year due to her antipathy toward society. She only looked for a new job when her loneliness became intolerable. Finally, she chose a community center for people with mental disorders (hereafter, O center) so that she could feel superior to other attendees, but soon became enraged that she was considered their equal. This resulted in her choosing another vocational rehabilitation center for the unemployed (hereafter, P center). In both places, clients were able to obtain support from staff when needed. One man, Mr. C, who helped administer both facilities, took a liking to her and cared for her in any way he could, for instance by renting a luxurious apartment in which to live with her, driving her to any places she required, and cooking daily meals for her. She did not think that he cared for her; rather, she thought that she provided him with fantastic opportunities to serve her. She never accepted the idea that he was the right man for her, because he was not handsome or slim, which made her feel ashamed to be seen in his company. She rejected all sexual advances.

The main purpose of $\mathrm{O}$ center was to support people with mental disorders by providing both a peer group and a paying job that was uncomplicated and menial but important because it contributed to the upkeep of the center. Therefore, each client was ideally expected to work to their full potential. However, Ms. B was unable to focus on her assigned task; instead, she was too preoccupied with the difference in position between her and the female staff. She thought it was unfair that women whose schooling she deemed inferior to hers were in a position to guide and direct her. This hostility was intensified by her umbrage at working for a low wage. She could only find flaws in the center's way of operating and decry the abilities of its staff. She took it upon herself to protest to Mr. C on behalf of other clients, many of whom had only expressed minor complaints in passing. She told him that she was the most qualified person to provide seriously mentally ill clients with guidance regarding etiquette and manners, and to secure their employment in ordinary jobs. Further, she demanded to be utilized in such a way. Mr. C, who did not want to be disliked by Ms. B, tried to comply. He acknowledged her skills and 
recommended that she provide counseling to those clients. However, before this plan was realized, Ms. B was employed by a company (hereafter referred to as company X) whose general manager, Mr. D, was a friend of Mr. C. It was less than a month before she started complaining to her therapist that Mr. D was jealous of her talent, and criticizing the company's management policies. She also expressed anger that almost none of her colleagues noticed or respected her talent. She said she would be headhunted by company Y, and abruptly quit company X. Not surprisingly, a job offer from company $\mathrm{Y}$ was not forthcoming, and she again became unemployed. She then started attending P center, where Mr. C managed the programs. According to her, she used Mr. $\mathrm{C}$ and was not dependent on him.

Clients at P center were paid temporary welfare benefits, which provided them with opportunities to learn new job skills and improve their future employability. The majority of clients were less interested in the learning programs than in the welfare benefits, as the latter paid for their expenses while they looked for work. Immediately after starting work at the P center, Ms. B again came to devalue and denounce some staff. She was always fixated on the idea that she should be allocated a position that would make her superiority clear to the staff. Mr. C, during lectures, raised the possibility that P center clients might work at a community center for people with mental disorders, using the $\mathrm{O}$ center as a frame of reference for what their work would be like. When he explained that the $\mathrm{O}$ center staff members were paid a bonus, Ms. B could not control her rage and started protesting, and even insisted on the dismissal of majority of the staff as she judged them to be incompetent. At first, some clients in the class supported neither Mr. C nor Ms. B, but instead were amused by what they perceived as a lovers' quarrel. But gradually, as her aggression intensified, they came to express discomfort and nobody took her side. Later, Ms. B was informed that she invited antipathy from the clients, although up to that point she had perceived herself to be their representative in a protest against the management. When she was told that she was criticized by other clients, she felt intolerable shame and was not able to go to the center anymore.

In order to contextualize Ms. B's narcissistic personality, the author would like to describe her life history. Her father was frequently violent toward her mother and older brother, both of whom had developmental disorders. Given her mother's disorder and the fact that she prioritized her son's safety, she did not provide Ms. B with sufficient emotional support or empathy. In addition, she was unable to manage Ms. B's grandiose self and simply obeyed her commands. Her father showed blind, unreasoning love to Ms. B when she met his standards, and Ms. B was very quick to learn that anything below his standards should be hidden from him. She devalued her mother and brother as her father did. Due to the lack of her mother's empathetic support and her father's blind love as long as she was a desirable daughter, she became ashamed to be seen in any situation in which she might be judged as inferior to others. Throughout her life, she has had low self-esteem, which she kept well hidden. Her pride did not allow her to reveal her shame or feelings of inferiority to others, which led to her generally aggressive attitude. Taking a passive role would mean that she was controlled, which was unbearable for her. Since adolescence she devalued other women and harbored feelings of superiority, behind which, however, lay intense envy. This brought about her difficulties in communicating on an equal level with her peers. She always supposed that other women were envious of her skills and popularity. At the company where she worked for about 10 years in her twenties, she devalued the female staff and tried to develop close relationships with a few men as well as one woman, Ms. D, who she idealized and regarded as a potential ally. She used these people as job advisors and to provide comfort when she experienced painful feelings provoked by conflict at that job.

While the actions of Ms. $\mathrm{B}$ at the $\mathrm{O}$ and $\mathrm{P}$ centers derived from her narcissistic personality, she did not act in a comparable fashion at the company where she worked in her early twenties, and she was able to continue working there for about 10 years. One of the reasons for this was her handsome "popular" partner in an adulterous relationship, which made her feel superior to all the other women at the company. Moreover, she had a female colleague, Ms. D, two years her senior, toward whom she occasionally felt ambivalent if emotional support was withheld, but who nevertheless functioned as an object of Ms. B’s “twinship transference” (1971). This woman's support, which differed from Mr. C's special treatment, was grounded in a sense of reality that sometimes fueled Ms. B’s anger. When Ms. B was not pleased with the woman's behavior she verbally attacked her, in one instance throwing tea at her. Furthermore, the characteristics of the company also seem to have influenced Ms. B's self-esteem. The company was famous in the prefecture, and its ambitions for growth were based on a single tangible target, namely increasing sales. In order to make this possible, it was necessary that every staff member made an effort to perform better. Although Ms. B harbored unrealistic grandiose narcissism and envy, these characteristics were not transformed into negative actions within the company's practical atmosphere because Ms. B perceived that she had been assigned a role that satisfied her pride in a company with which she identified. 
Conversely, at the O and P centers, Mr. C devoted himself to taking over Ms. B’s tasks, which undermined her independence.

It would also be germane at this point to briefly examine the $\mathrm{O}$ and $\mathrm{P}$ centers with regard to group mentality, each client's attitude towards attendance, and Ms. B's reaction towards them. Ms. B's rage and furious protests might have been caused by her difficulty accepting that she was attending a facility for individuals without a job or with a mental disorder, as well as by her self-perception as superior to all other clients and staff. However, there is still room to consider other factors. At the O center, clients' motivations for participation were not necessarily spontaneous, due to personal factors such as weak ego function caused by mental disorders and the fact that they felt societally impelled to engage in some form of social contact. Even accepting that every client, to a varying degree, had a spontaneous motivation, they also had needs for both a place and community that could alleviate their past painful experiences with familial and/or extra-familial relationships. Indeed, in Japan almost all community centers for people with mental disorders mention that they offer an "ibasyo (a place of their own)" for those who need to be accepted by others. This would help foster "basic assumption dependency" (baD), proposed by Bion (1961), in the centers' day-to-day operations. Another characteristic of these centers is that the goals of clients' tasks are not clearly defined. Nor are tasks diversified; every client is required to perform the same job, with none of these jobs assigned on the basis of clients' respective strengths and weaknesses. Clients tend not to acknowledge their limitations or cooperate with other people. All of these factors significantly reduce the opportunity for clients to foster their self-confidence. Mr. C's special treatment of Ms. B, using "instrumental support," satisfied her narcissism but paralyzed her reality testing, which led to her irrational protests at the $\mathrm{P}$ center.

At the P center, the clients were not necessarily satisfied with the center and staff, but they depended on them for their welfare benefits. Ms. B's aggressive acts undermined this system, which made her a target of clients' criticism. Ms. B was similarly dependent on the $\mathrm{P}$ center, but her ambition to attain a privileged position within it drove her to try to become a leader and to attempt to control the group. At the $\mathrm{O}$ center her ambition was partially attained, possibly because other clients' ego function was so vulnerable due to mental disorders, which made it easy for Ms. B to control them. At the P center, the majority of clients did not have mental disorders and they could sense that Ms. B's actions would damage group function. Using Bion's term, Ms. B's "basic assumption fight/flight (baFF) valence," in other words her attempts to eliminate some staff members, provoked strong conflict with the group, resulting in her exclusion from it.

The author would like to summarize Ms. B's ways of relating to a group. She was unable to face the anxiety of probable rejection, and focused on controlling the group by force, since to her it was an object that she assumed would fulfill her needs of being admired. This can be partially understood as the result of a reactionary aggressive attitude that caused Ms. B to act in a way that would negate her fear of being placed in the passive position of receiving care from the center and staff. After leaving the P center, Ms. B benefited from Mr. C's knowledge and personal relationships and succeeded in establishing a non-profit welfare organization to help disabled people obtain jobs, and she was convinced she was the most capable person of doing so. However, this venture lasted less than a year, as Mr. C left Ms. B, which she perceived as abandonment.

\section{Discussion}

The two women described in this article had difficulties adapting to the groups to which they belonged because their minds were always occupied by others' evaluation of them. Although they manifested contrasting behaviors, both experienced problems related to unresolved narcissistic needs. After mental breakdown and before rehabilitation, they stayed at home, and their narcissistic needs were partially satisfied within individual psychotherapy as well as by family members' support. However, once they again returned to society, such needs were not necessarily met. While these two cases are extreme regarding their primitive narcissistic need for approval, a considerable proportion of people likely share this need to a lesser degree. The two women are characterized by the fact that they tried to use groups to satisfy their approval needs, which were previously unmet by their mother, the primary object. Whether this intention was partially realized or not depended not only on the patients' personalities but also on the characteristics of the group, such as the group mentality and the attitude of group members toward them. As seen in the case of Ms. A, when the individual's dependency needs are intense, they can be satisfied by the group in an environment where the establishment of "self" is not highly valued, in her case, in a rural area. In such areas, people care for each other and sometimes interfere in each other's per- 
sonal lives. As seen in Ms. A's case, the needs of those with intense narcissistic dependency are not met within the individualistic atmosphere of contemporary urban culture.

In the case of Ms. B, the workplace of her twenties had a clearly defined practical goal; specifically, the workplace functioned as a "work group" (WG) whose goal was not undermined by the "basic assumption group" (ba group) (both Bion's terms). Furthermore, she was allotted a position that satisfied her pride. Even though it was extremely difficult for her to recognize her own limitations and to cooperate with other people, she was able to continue the job for about a decade, due to the aforementioned factors as well as the availability of older female staff and a man she was in an adulterous relationship with, all of whom functioned as objects of her self-object transference (Kohut, 1971). In contrast, she found it completely unacceptable to work in the community program for people with mental disorders and the vocational rehabilitation center for the unemployed. As a result, she devalued the staff, other clients, and the facilities, in a highly outspoken fashion. Her attitudes and behaviors made the group members insecure because maintaining the WG function was led led to crisis. These groups were characterized by the "baD," under which clients were characterized by an extremely low degree of spontaneity and a dependency on the system and its managers. The clients' day-to-day complaints should be understood as expressions of dependency. This dependency would be partially utilized for the WG to maintain its function as a welfare group. However, Ms. B hated the peaceful dependent relationship between the clients and the managers, the latter who she envied intensely and tried to eliminate so that she could take their place. Her attitudes could be seen as a sign of her high "baFF valence" (Bion, 1961). Although she was not able to eliminate several staff members she particularly hated, Mr. C’s special treatment satisfied her unrealistic narcissism to some degree. She had been undergoing psychotherapy for several years before she met Mr. C. However, Mr. C's materialistic support led her to disengage from her original psychotherapeutic goal— to develop insight based on the therapist's nonmaterial support. Instead, she concentrated more on her triumphs involving Mr. C, although she never missed a therapy session. After the shocking loss of Mr. C and the subsequent collapse of her unrealistic grandiose self, which had depended on him, she once again sought her therapist's care. Envy towards managing staff made her deny her dependence on them, and she became a client who could disrupt the group dynamic to a critical degree. Since most clients at the $\mathrm{O}$ center had mental disorders, their ego function was relatively weak, and thus Ms. B was able to control them to some degree and she experienced no criticism from them. The $\mathrm{O}$ center clients had no collective concept of group maintenance. Conversely, the $\mathrm{P}$ center clients wanted to maintain the group. This discrepancy between Ms. B and the other clients resulted in her being criticized by them, because her attitudes and behaviors triggered their insecure feelings. Ms. B, as usual, left the group because she was confronted by the fact that she was not accepted by others and was not able to control them.

As noted previously, almost all of the community centers for people with mental disorders in Japan offer "ibasyo" (a place of their own), because a considerable proportion of people with mental disorders lose their place in society, and sometimes also in the family due to emotional rejection by family members. Ms. B's case is not unusual: a significant proportion of clients are reluctant to attend, viewing the centers as a place of last resort. In these centers, many clients experience an increase in their narcissistic needs for approval, and it is not uncommon to see rivalry between clients concerning pecking order, a dynamic that can be regarded as one form of the "basic assumption group" (Bion, 1961). If each client were assigned a role appropriate to their respective strengths, there would be a lesser increase in their narcissistic needs for approval. Furthermore, their contribution to the WG would bring about others' respect within the group, leading to recovery of self-esteem. Providing clients with physical space is inadequate to facilitate the recovery of self-esteem; these centers should utilize the client's valence for the basic assumption group to convert it to a WG function. To make this possible, WG function in the workplace should be clearly defined. Colleagues' serving as objects of Ms. A and Ms. B's narcissistic transference; different colleagues inviting Ms. A to unofficial activities after-hours; Ms. B being assigned a practical role at the company she worked at in her twenties-all can seen as examples of the "specialized work group" (Bion, 1961), which, by containing the basic assumption group and neutralizing it, helps the WG maintain its function. Of these examples, the assignment of practical roles would be expected to bring about achievement-based self-esteem for each client.

The most prominent shared feature of the two cases above is the intense narcissistic need for approval. Both Ms. A and Ms. B always needed objects to accept their narcissistic transference (Kohut, 1971). They were not able to concentrate on any task without thinking of others' evaluation of them. This phenomenon reflects the lack of what Winnicott (1958) described as the "capacity to be alone" (p. 33, lines 26-28), "based on the expe- 
rience of being alone in the presence of someone." He writes that the origin of this capacity is "the infant's awareness of the continued existence of a reliable mother, whose reliability makes it possible for the infant to be alone and to enjoy being alone, for a limited period,” (p. 33, lines 23-26), and that this stage is attained by the fact that "the mother [is] preoccupied with her own infant and oriented to the infant's ego requirements through her own identification with her own infant" (p. 33, lines 13-15). Both women had early life experiences, not mentioned in this article, that indicated they were not able to experience their mother's preoccupation with them, or the "ego-supporting mother" (Winnicott, 1958), due to their mothers' deficient empathetic ability, and this played a major role in their group maladjustment in later life.

While acknowledging that the two cases described in this article are extreme, several Japanese psychiatrists point out that a narcissistic need for approval is a common and growing phenomenon, particularly among young Japanese people. Nishizono (1999) argues that the development of people's narcissistic tendencies in Japan has its origin in the collapse of the hereditary system. Before the modern era, the strong ties between "ie" (family) and "mura" (village) communities meant that people were expected to take a role in maintaining traditions and culture within family lines from generation to generation, and thus an individual's narcissistic needs were pushed aside. According to Doi (2001), a Japanese person is able to have "jibun" (self) "when he can maintain an independent self that is never negated by membership of the group" (p. 134, lines 26, 27). When this proves to be impossible and he puts his interests before those of group, he invites criticism. In this situation, "he is obliged, therefore, to choose to belong to the group even at the cost of obliteration of his self," (p. 135, lines 7, 8) because the "group for him is basically a vital spiritual prop, to be isolated from which would be, more than anything else, to lose his 'self' completely in a way that would be intolerable to him” (p. 135, lines 3-6). In Japanese traditional society, in other words, gaining the approval of the community depended on people suppressing their own narcissistic needs and attuning to others. Nishizono (1999) further writes that in contemporary society, where the hereditary system no longer holds and the connection between "mura" and "ie" is weakened, people have become more likely to pursue economic satisfaction and establish a sense of self based on external standards, which has driven them to compete and has led to feelings of isolation and often a sense of failure. He proposed the concept of the "circle-based self," which allows people to temporarily alleviate feelings of isolation by seeking external approval through the internet and mobile phones. Means of establishing self and sound self-esteem were not a focus of study before the middle of the twentieth century, but have become important themes in contemporary clinical psychiatry (Uji, 2013).

Saito (2013), a Japanese psychiatrist working with young patients with mental disorders, writes that in the near past when Japan was in its period of high economic growth (1954-1973), people were approved of when they worked diligently. He states that after this period, society rushed into the postmodern era, characterized by an information-oriented society and diverse set of values. As a result, the society shifted its focus away from diligence, and people have become more likely to be evaluated based on their ability to project themselves in various ways according to the societal group setting. Under the vague standards he describes, communication ability, which might manifest, for example, in the ability to read a social situation and make people laugh, is highly valued, in particular among young people. He says that the degree of skill in this area defines each member's individual personality characteristics, not necessarily accurately, after which they are allowed to join the group. To explain approval, he uses an analogy: youths who have withdrawn from society have conflicting feelings about it, while youths with personality disorders always recklessly try to win it. The traits and behaviors of Ms. A and Ms. B are both consistent with his definition of personality disorder. In order to be approved within the group, Ms. A provided services, sometimes by sacrificing herself, and Ms. B vociferously stressed her abilities.

\section{Conclusion}

The author would like to propose how mental health professionals should support patients' attempts to reintegrate into society. These efforts should be partially understood as a means of seeking objects that will approve unmet narcissistic needs. In welfare community centers that support patient recovery, professionals should adopt an approach whereby patients can recover self-esteem and spontaneity; this should be done through acceptance, approval, support of the patient's sense of reality, and the assigning of roles based on individual strengths, because the narcissism of most patients has been damaged due to the experience of illness. Meticulous counseling or psychotherapy is also essential, specifically by empathizing with patients' narcissistic pride and its damage by addressing their "reality ego (or the remnants of the reality ego)" (Kohut, 1971, p. 178). Since the two cases 
analyzed in this article were diagnosed with personality disorders and had highly intense narcissistic needs, the treatment strategies outlined here will not always be appropriate for patients with other diagnoses. While recognizing this as a limitation of this study, the author believes that the dynamic interaction between an individual's personality and the group mentality is an often overlooked phenomenon that clinicians, should they engage with it, will find useful in helping their patients’ reintegration into society.

\section{Acknowledgements}

The author would like to express deep gratitude to the two patients, as well as to Emeritus Professor of Fukuoka University, Masahisa Nishizono, who supervised her in treating these patients. There is no conflict of interest to declare.

\section{References}

Bion, W. (1961). Experiences in Groups and Other Papers. London and New York: Routledge. http://dx.doi.org/10.4324/9780203359075

Doi, T. (2001). The Pathology of Amae. In T. Doi (Ed.), Anatomy of Dependence (pp.101-141). Tokyo: Kodansha.

Freud, S. (1914). On Narcissism: An Introduction. In J. Strachey (Ed.), On the History of the Psychoanalytic Movement: Papers on Metapsychology and Other Works (pp. 67-102). London: Hogarth Press.

Kohut, H. (1971). The Analysis of the Self. Chicago and London: The University of Chicago Press.

Nishizono, M. (1999). Pathology of Circle-Based Self and Psychotherapy. Japanese Journal of Psychotherapy, 25, $444-447$. [In Japanese]

Saito, T. (2013). Shonin Wo Meguru Yamai (Illness Concerning Approval). Tokyo: Nippon Hyoron Sha Co. Ltd. Publishers. [In Japanese]

Uji, M. (2013). The Role of Clinical Psychiatry in Nurturing Autonomy in Female Japanese Patients with Pathological Personality Traits. Journal of Clinical Research and Bioethics, 4, 158. http://dx.doi.org/10.4172/2155-9627.1000158

Winnicott, D. W. (1958). The Capacity to Be Alone. In D.W. Winnicott (Ed.), The Maturational Processes and the Facilitating Environment (pp. 29-36). London: Karnac Books. 